\title{
Mid-upper arm circumference cut-off for detection of severe acute malnutrition in infants aged between one and six months
}

\author{
S.D. J. ${ }^{1}$, L. Bendre S. ${ }^{2 *}$, S. Desai A. ${ }^{3}$ \\ DOI: https://doi.org/10.17511/ijpr.2020.i08.07 \\ 1 Jyothi S.D., Associate Professor, Department of Paediatrics, Belagavi Institute of Medical Sciences, Belagavi, Karnataka, India. \\ 2* Spoorthi L. Bendre, Senior Resident, Department of Paediatrics, Mysore Medical College and Research Institute, Mysore, Karnataka, \\ India. \\ 3 Arunkumar S. Desai, Former Head of the Department, Department of Paediatrics, Belagavi Institute of Medical Sciences, Belagavi, \\ Karnataka, India.
}

Objective: To find the MUAC cut-off for detection of severe acute malnutrition in infants between 1 to 6 months of age. Material and Methods: A prospective observational study at IPD and OPD of a tertiary care hospital. 303 infants between one and six months of age above the length of $45 \mathrm{cms}$ were included in the study. In infants between one and six months of age, the length, weight, and MUAC were measured. SAM infants were identified using the WHO definition. Sensitivity, specificity, and Youden index for a particular MUAC was calculated in SAM infants. Results: $11 \mathrm{cms}$ was found to have a sensitivity of $85.1 \%$ and specificity of $65.9 \%$. It had the maximum Youden index of 0.55 with a positive likelihood ratio of 2.79 and a negative likelihood ratio of 0.21 . Conclusions: MUAC of $11 \mathrm{cms}$ can be used as a cut-off for SAM infants between 1 to 6 months of age. MUAC does not vary with gender. Weight and MUAC are significantly lower in SAM infants. But there is no difference when it comes to length as in acute malnutrition, the weight and MUAC are affected but length is not.

Keywords: MUAC, Cut-off, SAM, Infants, Malnutrition, Severe acute malnutrition

\section{Corresponding Author}

Spoorthi L. Bendre, Senior Resident, Department of Paediatrics, Mysore Medical College and Research Institute, Mysore, Karnataka, India.

Email: spoorthilb@gmail.com

\section{How to Cite this Article}

Jyothi SD, Bendre SL, Desai AS. Mid-upper arm circumference cut-off for detection of severe acute malnutrition in infants aged between one and six months. Pediatric Rev Int J Pediatr Res. $2020 ; 7(8): 430-436$.

Available From

https://pediatrics.medresearch.in/index.php/ijpr/arti cle/view/643
To Browse

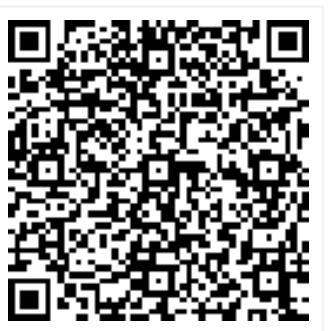

Manuscript Received 2020-12-10

Conflict of Interest No

Review Round 1
$2020-12-20$
Funding
Nil

$\begin{gathered}\text { Review Round } 2 \\ 2020-12-24\end{gathered}$
Ethical Approval
Yes

Review Round 2

Yes
Review Round 3

Accepted 2020-12-28

Plagiarism $\mathbf{X}$-checker $5 \%$

Note

Dy Jothi S.D., Spoorthi L. Bendre, Arunkumar S. Desai and Published by Siddharth Health Research and Social Welfare Society. This is an Open Access article licensed under a Creative Commons Attribution 4.0 International License https://creativecommons.org/licenses/by/4.0/ unported [CC BY 4.0]. 


\section{Introduction}

Undernutrition accounts for nearly half of all deaths in children under five globally. 17 million children suffer from Severe acute malnutrition globally [1].

Undernutrition accounts for $22 \%$ of the burden of disease in India. It adversely affects the economic growth of the country with an estimated adult productivity loss of $1.4 \%$ of GDP. Childhood undernutrition accounts for $45 \%$ of Under 5 mortality alone and remains a key public health challenge in India [2]. The maximum prevalence of wasting was seen in Jharkhand (29\%) and the minimum in Kerala (15.7\%). Prevalence of SAM in Karnataka is $10.5 \%$ and in Belgaum $16 \%$ [3].

The number of underweight children in India is among the highest in the world and is nearly double that of Sub-Saharan Africa. $19.8 \%$ of Indian underfive children are wasted and $6.4 \%$ of under-five children are severely wasted, which would translate to almost astounding 8 million children in India who are severely wasted out of the 25 million children who are wasted. The prevalence is even higher in infants below 6 months of age i.e., 13.1\%. [2]. The mortality due to SAM in infants less than 6 months is higher compared to that of children between 659 months of age [4].

Early infancy is the representation of a period of transition from neonatal life to childhood during which there is rapid growth, neurological and immunologic development, and changes in the mode of feeding. Nutrition programs and surveys have usually excluded infants under 6 months of age because adequate nutrition is assumed to be ensured by breastfeeding [5]. However, there is increasing recognition that malnutrition occurs before age 6 months and is associated with higher mortality $[6,7]$.

An analysis of Demographic and Health Survey data reported that, worldwide, 4.7 million under 6 months' infants have moderate acute malnutrition and 3.8 million have severe acute malnutrition (SAM), diagnosed by using the weight-for-length $z$ score (WLZ) [8]. In children above 6 months, midupper arm circumference (MUAC) is more discriminatory for mortality than is WLZ [9].

Relations between anthropometry and mortality may be confounded by age, HIV, or low birth weight arising from prematurity or small-for-gestationalage status.
Low-birth-weight infants could have been classified as malnourished by anthropometry at a single time point despite growing normally. Because of these concerns, the WHO and a recent Child Health and Nutrition Research Initiative exercise have highlighted establishing diagnostic criteria for SAM among Under 6 months' infants as the leading research question in the field. $[10,11]$.

Severe acute malnutrition (SAM) in infants less than 6 months of age is defined by World Health Organization (WHO) and UNICEF as an infant more than $45 \mathrm{~cm}$ in length having any of the following features: (i) weight for length below -3 standard deviation (SD or Z scores) of the median WHO growth reference; and/or (ii) visible severe wasting; and/or (iii) presence of bipedal edema; for children less than $45 \mathrm{~cm}$ in length, visible severe wasting is used as the criteria [10-14]. The role of MUAC in the diagnosis of SAM below the age of 6 months of age has not been considered adequately.

Mid-upper arm circumference (MUAC) cut-off of $11.5 \mathrm{~cm}$ is used as an independent diagnostic criterion to identify severe acute malnutrition (SAM) in children aged between 6 months and 5 years [15]. MUAC is useful for mass screening and community diagnosis. Mid-upper arm circumference has many advantages overweight for the length. It is cheap, quick, simple, and acceptable. Colour coded tapes allow the illiterate field workers and mothers to easily diagnose SAM, [12] whereas weight for length assessment requires- scales, a length board, which are troublesome to transport, and sufficient numeracy and literacy to convert the raw measurements into a weight for length category.

In a few studies, it has been found that MUAC has a better sensitivity than Weight for length for predicting mortality [13].

Hence, in the present study, it was aimed to find the MUAC cut-off for SAM in infants between 1 to 6 months of age.

\section{Materials and Methods}

Study design: A prospective observational study

Inclusion criteria: Infants between one and six months of age above the length of $45 \mathrm{cms}$.

Exclusion criteria: Infants with clinical evidence of

- edema

- ascites 
- c) pleural effusion

- d) significant tumor or organomegaly

Setting: OPD and IPD infants between 1 and 6 months fulfilling inclusion and exclusion criteria were included in this study.

Duration: For 1 year, between January 2018 to December 2018.

\section{Sample size:}

Formula $\mathrm{n}=\mathrm{Z} 2 * \mathrm{p} * \mathrm{q} / \mathrm{d} 2$

$Z=z$ value for alpha error $=1.96$

$p=$ prevalence $(20.9)[14]$

$q=100-p$

$\mathrm{d}=$ absolute error $10 \%$

$\mathrm{n}=1.962 \times 20.9 \times 79.1 / 10 \times 10$

$=63$ with $10 \%$ error

Based on this a minimum of 63 infants were taken in each group. Total of 303 infants were included in this study.

\section{Method of collection of data}

The particulars of the infant and relevant history were taken.

The length of the child was measured by an infantometer. The child was made to lie on his back on the measuring board, positioning the crown of the head against the headboard compressing the hair. The head was held and tilted upwards until the eyes look straight up and the line of sight was perpendicular to the measuring board. The knees were straightened as much as possible. The soles of the feet were flat on the foot piece, toes pointing straight up. The length was recorded to the nearest centimeter [15].

MUAC was measured on the left upper arm. The midpoint between the acromion process and the tip of the olecranon was marked. The non-stretchable measuring tape was placed snugly around the arm at this point. It was measured to the nearest millimeter [15].

The weight of the child was measured with minimal clothing. Weight was measured using an electronic weighing scale (Goldtech weighing scales, ISO 9001:2008 certified, New Delhi, Delhi, India). Weight was measured to the nearest 10 grams [15].

Length, weight, and MUAC were recorded of all the infants taken in the sample.
The measurements were taken by the Principal Investigator or any postgraduate student.

The weight for length $Z$ scores was calculated according to 2006 WHO Multicentre Growth Reference Study (MGRS) growth curves using weight and length which were recorded.

The infants were divided into 3 groups based on age

(I) Between 1 to 2 and a half months (2 months 15 days)

(Ii) Between 2 and half months to 4 months

(Iii) Between 4 months to 6 months

The average MUAC, weight, and length for normal infants of the corresponding age groups were calculated.

One more group containing only SAM infants between the ages of 1 to 6 months was taken. Severe acute malnutrition (SAM) defined as an infant more than $45 \mathrm{~cm}$ in length having any of the following features: (i) weight for length below -3 standard deviation (SD or Z scores) of the median WHO growth reference; and/or (ii) visible severe wasting [8].

The average MUAC, weight, length of the SAM infants was calculated.

\section{Ethical clearance: Taken}

Statistical analysis: Basic data presented in percentages or proportions and graphs. A T-test was used to see the significant difference between MUAC of SAM and normal infants. Sensitivity, specificity, Youden index (sensitivity+specificity-1), and the likelihood ratio of positive and negative tests were calculated for MUAC cut-offs of $9.5 \mathrm{~cm}, 10 \mathrm{~cm}, 10.5$ $\mathrm{cm}, 11 \mathrm{~cm}, 11.5 \mathrm{~cm}$, and $12 \mathrm{~cm}$ against the presence of SAM (WLZ <-3). The receiver operating characteristic (ROC)curve was plotted. a p-value of $<0.05$ was taken as significant.

Youden index measures the effectiveness of the diagnostic test and enables the selection of an optimal threshold point (cutoff).

The positive likelihood ratio is the probability of a person testing positive divided by the probability of a person who does not have the disease testing positive. The negative likelihood ratio is the probability of a person who has disease testing negative divided by the probability of the person who does have not the disease testing negative. 


\section{Results}

Totally 303 infants were studied of which 67 were SAM infants. Among those infants who were not SAM, $42.3 \%$ (i.e., 100) infants were between 1 to 2 months 15 days, $27.5 \%$ (i.e., 65) were between 2 months 16 days to 4 months, $30.1 \%$ (i.e., 71) were between 4 to 6 months. In infants between 1 to 2 months 15 days, 56\% (56) were median, 28\% (28) were $<-1$ SD and $16 \%$ (16) were <-2SD. In infants between 2 months 16 days to 4 months, 58\% (38) were median, 23\% (15) were <-1SD and 19\% (12) were <-2SD. In infants between 4 to 6 months, $60.5 \%$ (43) were median, $22.5 \%$ (16) were <-1SD and $17 \%$ (12) were <-2SD. In the present study, in non-SAM infants between 1 to 2 months 15 days, the average length in males was $53.05 \pm 3.80 \mathrm{cms}$ and females $52.95 \pm 3.74 \mathrm{cms}$. There was no significant difference in length. In infants between 2 months 16 days to 4 months, the average length in males was $58.45 \pm 5.17 \mathrm{cms}$ and females $57.63 \pm 3.53 \mathrm{cms}$. There was no significant difference in length. In infants between 4 months to 6 months, the average length in males was $62.13 \pm 3.57 \mathrm{cms}$ and females $60.12 \pm 4.18 \mathrm{cms}$. There was a significant difference in length between males and females. $(p=0.034)$. In the present study, in nonSAM infants between 1 to 2 months 15 days, the average weight in males was $3.96 \pm 0.91 \mathrm{kgs}$ and females $3.96 \pm 0.83 \mathrm{kgs}$. There was no significant difference in weight. In infants between 2 months 16 days to 4 months, the average weight in males was $5.53 \pm 1.32 \mathrm{kgs}$ and females $4.87 \pm 0.88 \mathrm{kgs}$. There was a significant difference in weight in males and females. $(p=0.027)$ In infants between 4 months to 6 months, the average weight in males was $62.13 \pm 0.85 \mathrm{cms}$ and females $60.12 \pm 0.96 \mathrm{cms}$. There was no significant difference in weight between males and females. In the present study, in non-SAM infants between 1 to 2 months 15 days, the average MUAC in males was $11.11 \pm 1.51 \mathrm{cms}$ and females $11.12 \pm 1.42 \mathrm{cms}$. In infants between 2 months 16 days to 4 months, the average MUAC in males was $12.87 \pm 1.32 \mathrm{cms}$ and females $12.23 \pm 1.37 \mathrm{cms}$. In infants between 4 months to 6 months, the average MUAC in males was $13.24 \pm 3.57 \mathrm{cms}$ and females $12.69 \pm 1.34 \mathrm{cms}$. There was no significant difference in MUAC between males and females in any of the age groups. In SAM infants, the average length of males was $55.74 \pm 8$ $.93 \mathrm{cms}$ and females $55.22 \pm 7.42 \mathrm{cms}$, the average weight of males was $3.34 \pm 1.73 \mathrm{kgs}$ and females $3.19 \pm 1.31 \mathrm{kgs}$, the average MUAC of males was
$8.99 \pm 2.37 \mathrm{cms}$ and females $9.08 \pm 2.02 \mathrm{cms}$. There was no significant difference in the average length, weight, and MUAC between males and females who were SAM.

In the present study, the average weight of nonSAM infants was $4.92 \pm 1.31 \mathrm{~kg}$, and that of SAM infants $3.26 \pm 1.51 \mathrm{~kg}$. There was a significant difference in the weight between non-SAM and SAM infants. $(p=<0.001)$ The average length of non-SAM infants was $56.88 \pm 5.36 \mathrm{cms}$ and that of SAM infants was $55.46 \pm 8.1 \mathrm{cms}$. There was no significant difference in the length between SAM and non- SAM infants. THE average MUAC of non-SAM infants was $12.09 \pm 1.64 \mathrm{cms}$ and that of SAM infants was $9.04 \pm 2.18 \mathrm{cms}$. There was a significant difference in the MUAC between non-SAM and SAM infants. ( $p=$ $<0.001)$

In the present study, the average weight of the WLZ score of the median was $5.16 \mathrm{~kg},-1 \mathrm{SD}$ was $4.79 \mathrm{~kg}$, -2SD was $4.31 \mathrm{~kg}$ and $<-3 S D$ was $3.26 \mathrm{~kg}$. The average length of the WLZ score of the median was $56.39 \mathrm{cms}$, -1 SD was $57.76 \mathrm{cms}$, -2 SD was $57.23 \mathrm{cms}$ and <-3SD was $55.46 \mathrm{cms}$. The average MUAC of WLZ score of the median was $12.46 \mathrm{cms}$, -1 SD was $11.77 \mathrm{cms}$, $-2 \mathrm{SD}$ was $11.28 \mathrm{cms}$ and <-3SD was $9.04 \mathrm{cms}$.

Table-1: Evaluation of different cut-offs of MUAC for diagnosis of SAM.

\begin{tabular}{|l|l|l|l|l|l|l|}
\hline $\begin{array}{c}\text { S } \\
\text { no }\end{array}$ & $\begin{array}{c}\text { MUAC in } \\
\mathrm{cms}\end{array}$ & $\begin{array}{c}\text { Sensitivit } \\
\mathrm{y}(\%)\end{array}$ & $\begin{array}{c}\text { Specificity } \\
(\%)\end{array}$ & $\begin{array}{c}\text { Youden } \\
\text { Index }\end{array}$ & $\begin{array}{c}\text { Likelihood } \\
\text { ratio }+\end{array}$ & $\begin{array}{c}\text { Likelihood } \\
\text { ratio - }\end{array}$ \\
\hline 1 & $\leq 12.0$ & 95.5 & 44.9 & 0.40 & 1.73 & 0.10 \\
\hline 2 & $\leq 11.5$ & 89.6 & 62.3 & 0.52 & 2.37 & 0.17 \\
\hline 3 & $\leq 11.0$ & 85.1 & 69.5 & 0.55 & 2.79 & 0.21 \\
\hline 4 & $\leq 10.5$ & 67.2 & 80.9 & 0.48 & 3.52 & 0.41 \\
\hline 5 & $\leq 10.0$ & 64.2 & 86.4 & 0.51 & 4.73 & 0.41 \\
\hline 6 & $\leq 9.5$ & 53.7 & 91.9 & 0.46 & 6.67 & 0.50 \\
\hline
\end{tabular}

This shows that the MUAC cutoff for detection of SAM infants between 1 to 6 months of age is $11 \mathrm{cms}$.

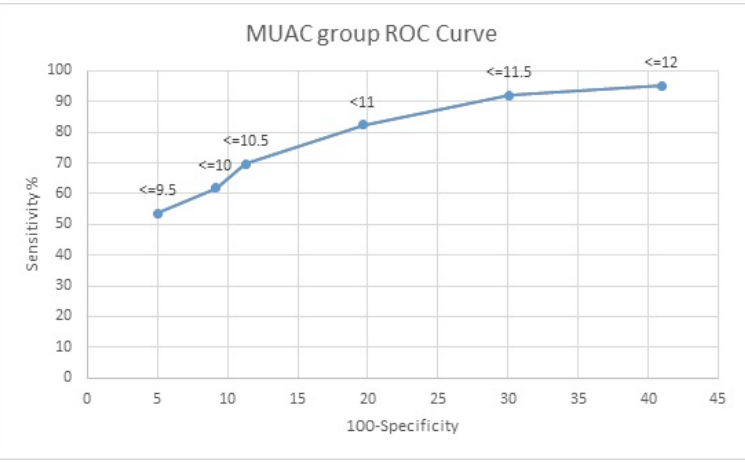




\section{Fig-1: ROC curve with MUAC plotted.}

The area under the curve is 0.84

P-value $<0.001$, shows that the MUAC cut-off of $11 \mathrm{cms}$ is very significant

\section{Table-2: Comparison of length based on WHO} charts.

\begin{tabular}{|c|c|c|c|c|}
\hline \multirow[t]{3}{*}{ Groups } & \multicolumn{4}{|c|}{ Length in $\mathrm{cms}$} \\
\hline & \multicolumn{2}{|l|}{ Male } & \multicolumn{2}{|l|}{ Female } \\
\hline & $\begin{array}{l}\text { Mean (SD) in } \\
\text { the present } \\
\text { study }\end{array}$ & $\begin{array}{l}\text { WHO } \\
\text { Chart } \\
{[16]}\end{array}$ & $\begin{array}{l}\text { Mean (SD) in } \\
\text { the present } \\
\text { study }\end{array}$ & $\begin{array}{l}\text { WHO } \\
\text { Chart } \\
{[16]}\end{array}$ \\
\hline $\begin{array}{l}\text { Infants between } 1 \text { to } 2 \\
\text { months } 15 \text { days }\end{array}$ & 53.05 (3.80) & $\begin{array}{l}50.5- \\
63.5\end{array}$ & 52.95 (3.74) & $\begin{array}{l}49.5- \\
62\end{array}$ \\
\hline $\begin{array}{l}\text { Infants between } 2 \text { and } \\
\text { half months to } 4 \\
\text { months }\end{array}$ & 58.45 (5.17) & $\begin{array}{l}55.5- \\
68\end{array}$ & 57.63 (3.53) & $\begin{array}{l}54- \\
66.5\end{array}$ \\
\hline $\begin{array}{l}\text { Infants between } 4 \text { to } 6 \\
\text { months }\end{array}$ & 62.13 (3.57) & $\begin{array}{l}59.7- \\
72\end{array}$ & $60.12(4.18)$ & $58-70$ \\
\hline
\end{tabular}

Table-3: Comparison of Weight based on WHO charts.

\begin{tabular}{|l|l|l|l|l|}
\hline \multicolumn{1}{|c|}{ Group } & \multicolumn{4}{|c|}{ Weight in kg } \\
\cline { 2 - 5 } & \multicolumn{2}{|l|}{ Male } & \multicolumn{2}{l|}{ Female } \\
\cline { 2 - 5 } & $\begin{array}{l}\text { Mean (SD) in } \\
\text { our study } \\
\text { charts } \\
{[16]}\end{array}$ & $\begin{array}{l}\text { Means (SD) } \\
\text { in our study }\end{array}$ & $\begin{array}{l}\text { WHO } \\
\text { charts } \\
{[16]}\end{array}$ \\
\hline $\begin{array}{l}\text { Infants between 1 to 2 } \\
\text { months 15 days }\end{array}$ & $3.969(0.91)$ & $3.4-6.6$ & $3.96(0.83)$ & $3.1-6.9$ \\
\hline $\begin{array}{l}\text { Infants between 2 and half } \\
\text { months to 4 months }\end{array}$ & $5.53(1.32)$ & $5.1-8.7$ & $4.87(0.88)$ & $4.1-8.2$ \\
\hline $\begin{array}{l}\text { Infants between } 4 \text { to 6 } \\
\text { months }\end{array}$ & $6.19(0.85)$ & $5.6-9.8$ & $5.73(0.96)$ & $5-9.3$ \\
\hline
\end{tabular}

\section{Discussion}

Among the total 303 infants, median were 137 $(45 \%),-1 S D$ were $59(19 \%),-2$ SD were $40(13 \%)$ and SAM $67(22 \%)$. In a study conducted by Chand et al, the number of infants with WLZ $>-2$, between -2 and -3 , and $<-3$, were $176(58.2 \%), 63$ $(20.9 \%)$, and $63(20.9 \%)$ respectively [14].

\begin{tabular}{|c|c|c|c|c|}
\hline \multirow[t]{3}{*}{ Groups } & \multicolumn{4}{|c|}{ Length in $\mathrm{cms}$} \\
\hline & \multicolumn{2}{|l|}{ Male } & \multicolumn{2}{|l|}{ Female } \\
\hline & $\begin{array}{l}\text { Mean (SD) in } \\
\text { the present } \\
\text { study }\end{array}$ & $\begin{array}{l}\text { WHO } \\
\text { Chart } \\
{[16]}\end{array}$ & $\begin{array}{l}\text { Mean }(S D) \text { in } \\
\text { the present } \\
\text { study }\end{array}$ & $\begin{array}{l}\text { WHO } \\
\text { Chart } \\
{[16]}\end{array}$ \\
\hline $\begin{array}{l}\text { Infants between } 1 \text { to } 2 \\
\text { months } 15 \text { days }\end{array}$ & 53.05 (3.80) & $\begin{array}{l}50.5- \\
63.5\end{array}$ & 52.95 (3.74) & $\begin{array}{l}49.5- \\
62\end{array}$ \\
\hline $\begin{array}{l}\text { Infants between } 2 \text { and } \\
\text { half months to } 4 \\
\text { months }\end{array}$ & $58.45(5.17)$ & $\begin{array}{l}55.5- \\
68\end{array}$ & $57.63(3.53)$ & $\begin{array}{l}54- \\
66.5\end{array}$ \\
\hline
\end{tabular}

\begin{tabular}{|l|l|l|l|l|}
\hline Infants between 4 to 6 months & 62.13 (3.57) & $59.7-72$ & $60.12(4.18)$ & $58-70$ \\
\hline
\end{tabular}

In the present study, despite the significant difference of length between male and female infants between 4 to 6 months and significant difference of weight between male and female infants between 2 months 16 days, and 4months, there is no significant difference in MUAC between male and female infants of corresponding age groups. This shows that MUAC does not depend on gender.

Total SAM infants taken in this study were 67 . Out of this, $46 \%$ (31) were males and $54 \%$ (36) were females. There was no significant difference in length, weight, and MUAC between male and female SAM infants.

The weight and MUAC of SAM infants were significantly lesser than that of non-SAM infants. But there was no difference in the length between them. In acute malnutrition, the weight and MUAC are affected but length is not.

The length didn't decrease based on the WLZ scores. But the weight and MUAC decreased as the WLZ scores reduced.

From the present study, $11 \mathrm{cms}$ was found to have a sensitivity of $85.1 \%$ and specificity of $65.9 \%$. It had the maximum Youden index of 0.55 with a positive likelihood ratio of 2.79 and a negative likelihood ratio of 0.21 . The area under the ROC curve was 0.84 and the $p$-value was $<0.001$ which showed that the MUAC cut-off of $11 \mathrm{cms}$ was highly significant. This was following to study by Chand et al MUAC cut-off $</=11.0 \mathrm{~cm}$ yielded the highest Youden index of 0.63 and highest specificity $(80.3 \%)$ and sensitivity (82.5\%).

The area under ROC curve was 0.884 and $p$-value $<0.001$ [14]. In a study by Mwagome et al, a single MUAC threshold of $11.0 \mathrm{~cm}$ measurement in infants around the age of vaccination (6-14 weeks) has predictive value concerning infant death and has shown that WFLz had poor predictive value concerning infant death [13]. A study by Murphy et al used $<11 \mathrm{cms}$ as screening MUAC for identifying infants between 2-6 months who were at risk of acute malnutrition [17].

\section{Conclusion}

MUAC cut-off of $11.5 \mathrm{cms}$ is used as an independent criterion for detection of SAM children between 6 months- 5 years. 


\section{What does the study add to the existing knowledge?}

MUAC cut-off of $11 \mathrm{cms}$ can be used as a cut-off for detection of SAM infants between 1- 6 months.

\section{Author's contribution}

Dr. Jyothi S.D.: Concept, study design

Dr. Spoorthi L. Bendre: Manuscript writing

Dr. Arunkumar S. Desai: Statistical analysis

\section{Reference}

01. UNICEF, WHO. The World Bank; Levels and Trends in Child Malnutrition. UNICEF-WHOWorld Bank Joint Child Malnutrition Estimates. 2017 May.

Available at [Article] [Crossref]

02. NFHS 3 data, based on WHO 2006 growth standards compiled by WHO.

Available at [Article] [Crossref]

03. NFHS 4 data, based on WHO 2006 growth standards compiled by WHO.

Available at [Article] [Crossref]

04. Management of Acute Malnutrition in Infants (MAMI) project. Emergency Nutrition Network, UCL Centre for International Health and Development. Action Contre la Faim. 2010. Available at [Article] [Crossref]

05. Lopirore C, Dop MC, Solal-Celigny A, Lagnado G. Excluding infants under 6 months of age from surveys- impact on prevalence of pre-school undernutrition. Public Health Nutr. 2007;10(1)79-87.

doi: $\quad 10.1017 / \mathrm{S} 1368980007219676 \quad$ [Crossref]

06. Vygen SB, Roberfroid D, Captier V, Kolsteren P. Treatment of severe acute malnutrition in infants aged $<6$ months in Niger. J Pediatr. 2013;162(3)515-521.

e3. doi: 10.1016/j.jpeds.2012.09.008 [Crossref]
07. Berkley JA, Ngari M, Thitiri J, Mwalekwa L, Timbwa M, Hamid F, et al. Daily co-trimoxazole prophylaxis to prevent mortality in children with complicated severe acute malnutrition- a multicentre, double-blind, randomised placebocontrolled trial. Lancet Glob Health. 2016;4(7)e464-e473.

doi: $10.1016 / \mathrm{S} 2214-109 \times(16) 30096-1 \quad$ [Crossref]

08. Kerac M, Blencowe $H$, Grijalva-Eternid C, McGrath M, Shoham J, Cole TJ, et al. Prevalence of wasting among under 6 month old infants in developing countries and implications of new case definitions using WHO growth standards- a secondary data analysis. Arc Dis Child. 2011;96(11)1008-1013.

doi: 10.1136/adc.2010.191882 [Crossref]

09. Myatt M, Khara T, Collins S. A review of methods to detect cases of severely malnourished children in the community for their admission into community-based therapeutic care programs. Food Nutr Bull. 2006;27(3)S7-23.

doi: $10.1177 / 156482650602735302$ [Crossref]

10. WHO. Guideline- Updates on the management of severe acute malnutrition in infants and children. Geneva, World Health Organization. 2013.

Available at [Article] [Crossref]

11. Angood C, McGrath M, Mehta S, Mwangome M, Lung'ahoM, Roberfroid $D$, et al. Research priorities to improve the management of acute malnutrition in infants aged less than six months (MAMI). PLoS Med. 2015;12(4)e1001812.

doi: 10.1371/journal.pmed.1001812 [Crossref]

12. Blackwell $N$, Myatt $M$, Allafort-Duverger $T$, Balogoun A, Ibrahim A, Briend A. Mothers Understand And Can do it (MUAC)- a comparison of mothers and community health workers determining mid-upper arm circumference in 103 children aged 6 months to 5 years. Arch Public Health. 2015;73(1)26.

doi: $10.1186 / \mathrm{s} 13690-015-0074-z \quad$ [Crossref] 
13. Mwangome M, Ngari M, Fegan G, Mturi N, Shebe $M$, Bauni $E$, et al. Diagnostic criteria for severe acute malnutrition among infants aged under 6 mo. Am J Clin Nutr. 2017;105(6)1415-1423.

doi: 10.3945/ajcn.116.149815 [Crossref]

14. Chand S, Shah D. Mid-upper arm circumference for detection of severe acute malnutrition in infants aged between one and six months. Indian Pediatr. 2015;52;528-529.

[Crossref]
15. WHO. Facility based care of severe acute malnutrition. Country Office for India. 2013; March.

Available at [Article] [Crossref]

16. WHO. WHO Child growth Standards. Available at [Article] [Crossref]

17. Murphy M, Abebe $K$, Mahony $S$, Barthorp $H$, Andert $\mathrm{C}$. Management of acute malnutrition in infants less than six months in a South Sudanese refugee population in Ethiopia. Field Exchange. 2017.

[Crossref] 